\title{
Enhancement of surface roughness for brittle material during rotary ultrasonic machining
}

\author{
Ankit Sharma ${ }^{1}$, Atul Babbar ${ }^{1}$, Vivek Jain ${ }^{1}$ and Dheeraj Gupta ${ }^{1}$ \\ ${ }^{1}$ Department of Mechanical Engineering, Thapar Institute of Engineering and Technology, 147004 Patiala, India
}

\begin{abstract}
Surface roughness is the key aspect which could increase the application of float glass by enhancing the machined hole quality. Glass is extensively used in microfluidic devices, bio-medical parts and biosensors. The core objective of the research study is to optimize the best parametric combination to achieve the least amount of surface roughness. The three major parameters which are used for designed experimental study are spindle speed, ultrasonic amplitude and feed rate. The least value of surface roughness is noticed at spindle speed (5000 rpm), vibration amplitude $(20 \mu \mathrm{m})$ and feed rate $(6 \mathrm{~mm} / \mathrm{min})$ which be adopted for increasing its functional application. Consequently, after optimizing the parameters, least value of surface roughness at hole internal region is revealed as $1.09 \mu \mathrm{m}$.
\end{abstract}

\section{Introduction}

With the advancement in the technology, demand for the optical surface finish and efficient machining is continuously increasing. Due to high chemical stability and incomparable thermo-mechanical properties, glass is widely used in optical transmission, lenses, reflectors, automotive glass, cockpit windows, and optical instruments. Glass is extensively used in microfluidic devices, bio-medical parts, array of deoxyribonucleic acid, biosensors [1]. Despite its excellent features, glass processing technology is facing a lot of challenges like low surface finish, chipping, tool wear, and subsurface damage. From the past few decades, various traditional and non-traditional processes like abrasive jet machining, laser beam machining, and ultrasonic machining has been used for glass machining[2-4]. Fang et al.[5]used turning on the ZKN7 glass and found high tool wear.

To overcome problems addressed in the above-stated literature, a new technique of rotary ultrasonic machining (RUM) is used in the present investigation. RUM combines the material removal mechanism of both ultrasonic machining and conventional grinding to achieve desired characteristics[6]. In rotary ultrasonic machining, a diamond impregnated tool is continuously rotated and fed towards workpiece by an electric motor and is actuated with suitable ultrasonic frequency. Sharma et al.[7]used a rotary ultrasonic machining process during drilling of a hole in float glass [8]. The investigation was carried out with three input parameters feed rate, amplitude and tool diameter to determine their effect on tool wear and chipping. Zhang et al. [9]performed an investigation in which the rotary tool was actuated with vibration for drilling in the optical K9 glass. It was noticed that using $20 \%$ ultrasonic power, $5000 \mathrm{rpm}$ speed, $0.01 \mathrm{~mm} / \mathrm{s}$ feed rate can lead to minimum surface roughness. In another study, Zhou et al. [10] reported a study in which rotary ultrasonic face grinding was used for the machining of $\mathrm{SiCp} / \mathrm{Al}$ composites. The set of parameters caused higher surface roughness were highlighted. Lee et al.[11]used a rotary ultrasonic drilling technique to drill a hole in the BK7glass. The results revealed that feed rate was the most dominating factors which influence the surface roughness. Liu et al.[12]observed significant improvement in the surface finish during the machining of carbon fiber reinforced plastic with the rotary ultrasonic machining. So, umpteen benefits of RUM process make it ideal for drilling hole in the glass. Therefore, the core objective of the current study is to optimize the best parametric combination to achieve the least amount of surface roughness. The three major parameters which are used for designed experimental study are spindle speed, ultrasonic amplitude and feed rate. Consequently, the surface roughness is the key factor which could enhance the machined hole quality and correspondingly increases its functional application.

\section{Experimentation}

A rotary ultrasonic machining (RUM) set up are used to generate holes in float glass specimen. A three-axis $\mathrm{CNC}$ vertical milling machine is modified into the RUM setup by installing ultrasonic generator, horn assembly and ultrasonic spindle as shown in Figure 1. The ultrasonic spindle has been worked with $20 \mathrm{KHz}$ 
of vibration and vibration amplitude could switch between 0 to $25 \mu \mathrm{m}$ by regulating the power supply. Using control panel, depth of drill, feed rate and spindle speed could adjusted by MDI program as per required designed experimental condition. A diamond coated hollow abrasive tool is used to perform whole experimentation. The diamond grains are electroplated on hollow tool faces. The mesh size abrasive is in range of 100 to 150 . The specification of the tool is stated as: tool length $(50.75 \mathrm{~mm})$, tool outer diameter $(7.86 \mathrm{~mm})$, inner diameter $(5.89 \mathrm{~mm})$ and abrasive coated lateral face $(3.15 \mathrm{~mm})$. Figure 1 shows the complete view of the hollow abrasive tool. The float glass specimen size is $148^{*} 85^{*} 5 \mathrm{~mm}\left(\mathrm{l}^{*} \mathrm{~b}^{*} \mathrm{~h}\right)$. It is a composition of silica, soda ash, salt cake, limestone, dolomite and small cullets. It has a tensile strength of $50 \mathrm{MPa}$, compressive strength of $212 \mathrm{MPa}$, Poisson' s ratio of 0.23 and Density ( $\rho$ ) of $2500 \mathrm{Kg} / \mathrm{m} 3$.

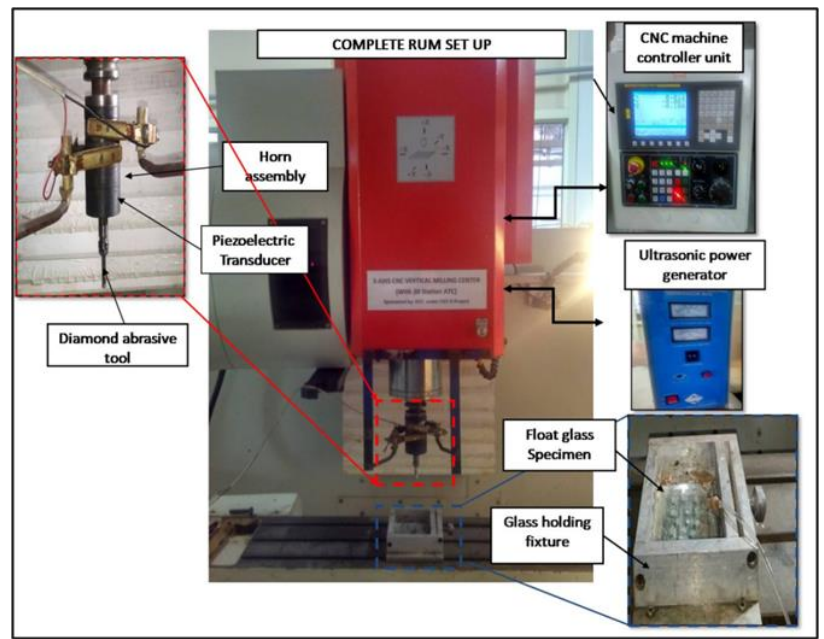

Figure 1. Illustration of complete rotary ultrasonic machining set up

L18 optimization Taguchi technique has been used in the experimental study. On the basis of industrial demand and experimental setup capacity, the three levels and factors of drilling parameters are selected as spindle speed: $3000,4000 \& 5000 \mathrm{rpm}$, ultrasonic amplitude: $0,10 \& 20 \mu \mathrm{m}$ and feed rate: $6,12 \& 18$ $\mathrm{mm} / \mathrm{min}$ and the output variable is surface roughness. 'Minitab software' is used to create a random experimental matrix arrangement for experimental procedure. The objective is to minimize the surface roughness with 'smaller-the-better' condition and transformed into mean and signal-to-noise $(\mathrm{S} / \mathrm{N})$ ratio values. After achieving all the drilling conditions, three holes are created at each designed parametric condition, which accumulating 54 experimental trials to attain the accurate result outcome. The drilled hole samples are then taken to quantify the surface roughness at the internal drilled region of float glass specimen. The result response is described in form of surface roughness. To evaluate the surface roughness of the internal region of the drilled hole, Mitutoyo surface roughness tester (Model: SJ 400) with cut-off length of $0.25 \mathrm{~mm}$ are used. Surface roughness quantification has been carried out on four different points on the inner surface of the drilled float glass hole specimen. Surface roughness $(\mathrm{Ra})$ is measured by moving the stylus on the inner region of the float glass samples parallel to its central axis. For smaller size of the float glass samples, the samples are sectioned into two pieces for the appropriate measurement.

\section{Results and Discussion}

By following L18 optimization technique, the designed matrix of experiments is described in Table 1 . In this technique, the signal noise $(\mathrm{S} / \mathrm{N})$ ratio and mean values are predicted by considering smaller-is-better order. Table 1 illustrates the input factors i.e. spindle speed, vibration amplitude and feed rate) along with response values of their respective mean and $\mathrm{S} / \mathrm{N}$ ratio of average surface roughness $(\mathrm{Ra})$ values for each designed experimentation. According to the requirement to nourish the surface characteristics of float glass specimen, the smallest amount of surface roughness at the internal region of the drilled hole leads to better hole quality.

Surface roughness $(\mathrm{Ra})$ readings are calculated four times at several positions axially parallel to the direction of drill feed and then its average surface roughness value is estimated using: $\mathrm{Ra}$ (Average $)=(\mathrm{Ra}$ $1+\operatorname{Ra} 2+\operatorname{Ra} 3+\operatorname{Ra} 4) / 4$ as mention in Table 1 . Figure 2 shows the response graph represents the $\mathrm{S} / \mathrm{N}$ ratio for the spindle speed, vibration amplitude and feed rate at hole internal region for surface roughness. Figure 3 describe the response graph represents the mean data for the spindle speed, vibration amplitude and feed rate at hole internal region for surface roughness. After visualizing the graphs (Figure 2 and Figure 3), it is noticed that increase in spindle speed from $3000 \mathrm{rpm}$ to $5000 \mathrm{rpm}$ possessed decrease in surface roughness ( $\mathrm{Ra})$. Whereas, feed rate shows an opposite trend that increase in feed rate from $6 \mathrm{~mm} / \mathrm{min}$ to $28 \mathrm{~mm} / \mathrm{min}$ would increase the surface roughness $(\mathrm{Ra})$ value. 


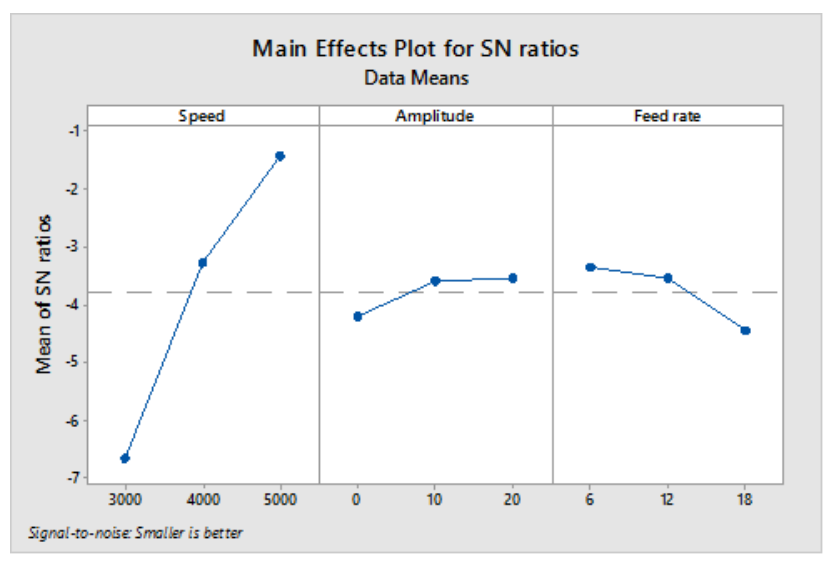

Figure 2. Response graph represents the $\mathrm{S} / \mathrm{N}$ ratio for the input factors w. r. t. surface roughness at hole internal region

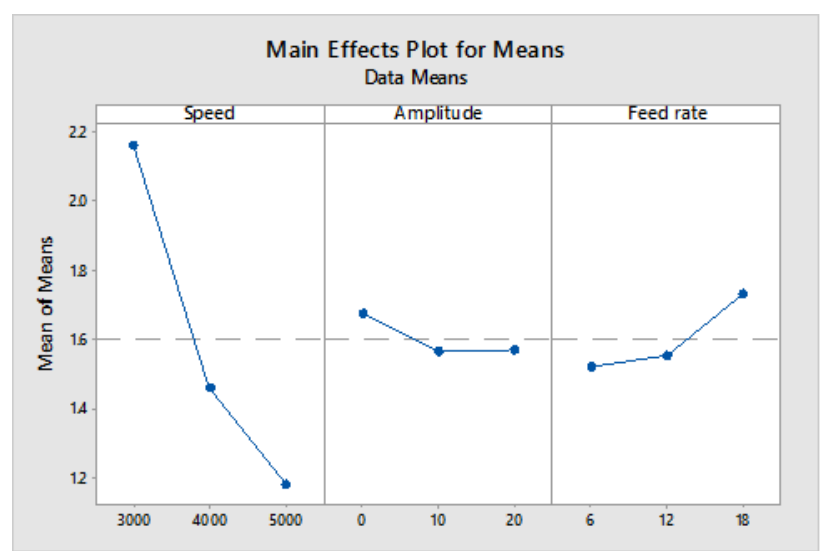

Figure 3. Response graph represents the mean data for the spindle speed, vibration amplitude and feed rate at hole internal region for surface roughness

Hence, it is clear that the combination of high spindle speed and low feed rate value would create enhanced surface quality. The reason of better surface roughness is that increase in spindle speed with less feed rate would lead the diamond abrasive of the hollow tool to cut and shear the hole's internal machined region for longer time span. On the contrary, larger feed rate would reduce the contact time of tool's abrasive with respect to drilled region which results as the worsening the surface roughness of the drilled specimen. Subsequently, it is revealed that the spindle rotation speed has more significant influence on the surface roughness. It is also predicted that the brittle material like float glass has generated lesser lateral crack, because of higher spindle speed that would provide shielding effects by the previous tool's abrasive that fascinate the decrease in surface roughness. But in case of higher feed rate, there may be a chance of increase in shear forces because the tool's abrasive would stay in contact for longer period during drilling operation [13]. As shown in Figure 2 and Figure 3, it is stated that the vibration amplitude value has drastic impact on the surface roughness of the machined region. It is found that, at vibration amplitude of $10 \mu \mathrm{m}$ and $20 \mu \mathrm{m}$, the surface roughness initiates decreasing. It is examined that the vibration amplitude has created the drilling discontinuous process in which the contact between the tool surface and hole internal periphery is oscillating constantly. This discontinuity leads to the generation of lesser shear and cutting force that would further makes the float glass specimen softer and resultant as a better hole quality.

As per ANOVA table of the $\mathrm{S} / \mathrm{N}$ ratio, it is confirmed that all three input factors have a significant effect on the surface roughness. Table 2 illustrates the value of $\mathrm{P}$ less than $5 \%(\mathrm{P}<0.05)$. As shown in Table 1 , it is mentioned that the least surface roughness (Ra) (avg.) i.e. $1.09 \mu \mathrm{m}$ is noticed at spindle speed $(5000 \mathrm{rpm})$ and vibration amplitude $(20 \mu \mathrm{m})$ and feed rate $(6 \mathrm{~mm} / \mathrm{min})$. Figure 4 depict the surface roughness profiles of the internal drilled region of float glass specimen: (a) Illustration of experiment no 3 with maximum surface roughness (Ra), (b) Profile of experiment no 16 with least surface roughness $(\mathrm{Ra})$ at optimum parameters.
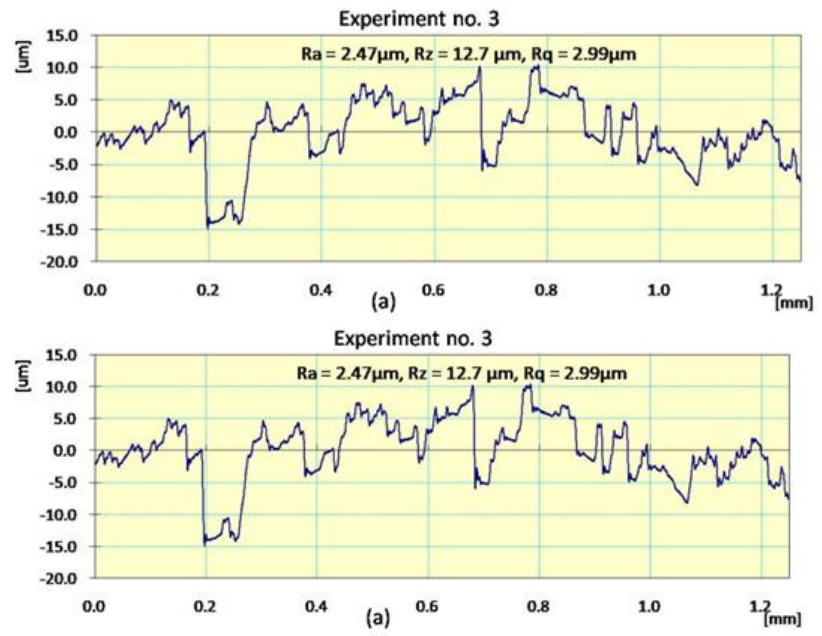

Figure 4. Surface roughness profiles of the internal drilled region of float glass specimen (a) experiment no 3 , (b) experiment no 16 at optimum parameter

Table 1. Illustration of input and response values table for surface roughness (average).

\begin{tabular}{|l|l|l|l|l|l|}
\hline $\begin{array}{c}\text { Exp. } \\
\text { no. }\end{array}$ & $\begin{array}{c}\text { Speed } \\
(\mathrm{rpm})\end{array}$ & $\begin{array}{c}\text { Amplitude } \\
(\mu \mathrm{m})\end{array}$ & $\begin{array}{c}\text { Feed rate } \\
\left(\mathrm{mm}^{3} / \mathrm{mi}\right. \\
\mathrm{n})\end{array}$ & $\begin{array}{c}\text { Mean of } \\
\mathrm{Ra}(\mu \mathrm{m})\end{array}$ & $\begin{array}{c}\text { S/N ratio } \\
\text { of Ra } \\
(\mu \mathrm{m})\end{array}$ \\
\hline 1. & 3000 & 0 & 6 & 2.20 & -6.84845 \\
\hline 2. & 3000 & 10 & 12 & 1.91 & -5.62067 \\
\hline 3. & 3000 & 20 & 18 & 2.47 & -7.85394 \\
\hline 4. & 4000 & 0 & 6 & 1.53 & -3.69383 \\
\hline 5. & 4000 & 10 & 12 & 1.45 & -3.22736 \\
\hline 6. & 4000 & 20 & 18 & 1.48 & -3.40523 \\
\hline 7. & 5000 & 10 & 6 & 1.12 & -0.98436 \\
\hline 8. & 5000 & 20 & 12 & 1.15 & -1.21396 \\
\hline 9. & 5000 & 0 & 18 & 1.30 & -2.27887 \\
\hline 10. & 3000 & 20 & 6 & 1.84 & -5.29636 \\
\hline
\end{tabular}




\begin{tabular}{|l|l|l|l|l|l|}
\hline 11. & 3000 & 0 & 12 & 2.24 & -7.00496 \\
\hline 12. & 3000 & 10 & 18 & 2.32 & -7.30976 \\
\hline 13. & 4000 & 10 & 6 & 1.35 & -2.60668 \\
\hline 14. & 4000 & 20 & 12 & 1.38 & -2.79758 \\
\hline 15. & 4000 & 0 & 18 & 1.58 & -3.97314 \\
\hline 16. & 5000 & 20 & 6 & 1.09 & -0.74853 \\
\hline 17. & 5000 & 0 & 12 & 1.19 & -1.51094 \\
\hline 18. & 5000 & 10 & 18 & 1.24 & -1.86843 \\
\hline
\end{tabular}

- The optimized parameters to get the least amount of surface roughness are spindle speed (5000 rpm), feed rate $(6 \mathrm{~mm} / \mathrm{min})$ and vibration amplitude $(20 \mu \mathrm{m})$.

- After optimizing the parameters, least value of surface roughness at hole internal region is revealed as $1.09 \mu \mathrm{m}$.

- To enhance the functional application of the float glass, hole's internal region is needed to be machined efficiently.

Table 2. Table illustrates the Analysis of Variance (ANOVA) for $\mathrm{SN}$ ratio for the surface roughness $(\mathrm{Ra})$.

\begin{tabular}{|l|l|l|l|l|l|}
\hline Source & $\begin{array}{l}\text { Degree } \\
\text { of } \\
\text { Freedom } \\
\text { (DOF) }\end{array}$ & $\begin{array}{l}\text { Sum of } \\
\text { squares } \\
\text { (SS) }\end{array}$ & Variance & F-ratio & $\begin{array}{l}\text { P- } \\
\text { value }\end{array}$ \\
\hline $\begin{array}{l}\text { Spindle } \\
\text { speed }\end{array}$ & 2 & 84.109 & 42.0544 & 203.43 & 0.000 \\
\hline Feed rate & 2 & 1.649 & 0.8246 & 3.99 & 0.050 \\
\hline $\begin{array}{l}\text { Vibration } \\
\text { amplitude }\end{array}$ & 2 & 4.004 & 2.0018 & 9.68 & 0.004 \\
\hline $\begin{array}{l}\text { Residual } \\
\text { Error }\end{array}$ & 11 & 2.274 & 0.2067 & & \\
\hline
\end{tabular}

As per ANOVA table of the $\mathrm{S} / \mathrm{N}$ ratio, it is confirmed that all three input factors have a significant effect on the surface roughness. Table 2 illustrates the value of $\mathrm{P}$ less than $5 \%(\mathrm{P}<0.05)$.

The maximum value of $\mathrm{Ra}-2.47 \mu \mathrm{m}, \mathrm{Rz}-12.7 \mu \mathrm{m}$ and $\mathrm{Rq}-2.99 \mu \mathrm{m}$ are found at designed parameters of spindle speed (3000 rpm), vibration amplitude $(0 \mu \mathrm{m})$ and feed rate $(18 \mathrm{~mm} / \mathrm{min})$ which should not be adopted for achieving least roughness value. At optimum parametric conditions, the surface roughness values of inner surface of float glass specimen are found as $\mathrm{Ra}-1.09 \mu \mathrm{m}, \mathrm{Rz}-7.3 \mu \mathrm{m}$ and $\mathrm{Rq}-1.42 \mu \mathrm{m}$. Figure 4 (b) shows the roughness profile at optimum condition. Hence, to achieve the overall hole quality, the combination of hole's side corners and inner machined region are needed to be machined efficiently without drilling defect.

\section{Conclusion}

The objective of the study is to optimize the best parametric combination to achieve the least surface roughness $(\mathrm{Ra})$ value. L 18 optimization technique is used while taking three input parameters (spindle speed, ultrasonic amplitude and feed rate). Based on the result outcomes, the following conclusions have been drawn:

\section{References}

1. M. Arif, M. Rahman, W.Y. San, Ultraprecision ductile mode machining of glass by micro-milling process, J Manuf Process, 13, 1 (2011). doi: 10.1016/j.jmapro.2010.10.004

2. X. Chen, J. Xiao, Y. Zhu, Micro-machinability of bulk metallic glass in ultra-precision cutting. Mater Design, 136, (2017). doi: 10.1016/j.matdes.2017.09.049

3. JD. Owen, MA. Davies, D. Schmidt, EH. Urruti, On the ultra-precision diamond machining of chalcogenide glass. CIRP Ann - Manuf Technol, 64,1 (2015). doi: 10.1016/j.cirp.2015.04.065

4. C. Heinzel, K. Rickens, Engineered wheels for grinding of optical glass. CIRP Ann - Manuf Technol. 58,1 (2009). doi: 10.1016/j.cirp.2009.03.096

5. FZ. Fang, LJ. Chen, Ultra-precision cutting for ZKN7 glass. CIRP Ann - Manuf Technol. 49,1 (2000).

6. RP. Singh, S. Singhal, Rotary Ultrasonic Machining: A Review. Mater Manuf Process 31, 1795-1824 (2016). doi: 10.1080/10426914.2016.1140188

7. A. Sharma, V. Jain, D. Gupta, Characterization of Chipping and Tool wear during drilling of Float glass using rotary ultrasonic machining. Measurement (2018). doi: 10.1016/j.measurement.2018.06.040

8. A. Sharma, V. Jain, D. Gupta, Multi-Shaped Tool Wear Study during Rotary Ultrasonic Drilling and Conventional Drilling for Amorphous Solid, Journal of Process Mechanical Engineering, 0,0: 1-10 (2018). doi: $10.1177 / 0954408918776724$

9. C. Zhang, W. Cong, P. Feng, Z. Pei, Rotary ultrasonic machining of optical K9 glass using compressed air as a coolant: A feasibility study. Proc Inst Mech Eng Part B J Eng Manuf 228, 504-514 (2014). doi: 10.1177/0954405413506195

10. M. Zhou, G. Dong Experimental Investigation of Rotary Ultrasonic Face Grinding of $\mathrm{SiCp} / \mathrm{Al}$ Composites. Mater Manuf Process, 31,5 (2016). doi: 10.1080/10426914.2015.1025962

11. MH. Lee, I. Sudin, GE. Ken, A. Zaharim, Parameters Optimization of Rotary Ultrasonic Machining of Glass Lens for Surface Roughness Using Statistical Taguchi' s Experimental Design. WSEAS Int Conf Proceedings Math Comput Sci Eng No 13, (2008).

12. J. Liu, D. Zhang, L. Qin, L. Yan, Feasibility study of the rotary ultrasonic elliptical machining of carbon fiber reinforced plastics (CFRP). Int J Mach Tools 
$\begin{array}{lll}\text { Manuf 53, 141-150 (2012). doi: } & \end{array}$ 10.1016/j.ijmachtools.2011.10.007

13. M. Mandegari, S. Behbahani, Experimental Analysis of a Novel Rotary Ultrasonic Assisted Drilling
(RUAD) Machine. Materials and Manufacturing Processes, 28, 481-487 (2013). doi: $10.1080 / 10426914.2012 .727122$ 